\title{
SERIOUS FRIVOLITY: EXPLORING PLAY IN UK SECONDARY MATHEMATICS CLASSROOMS
}

\author{
Elizabeth Lake \\ University of East Anglia, UCL Institute of Education, UK
}

As part of a PhD researching teacher's positive emotions in secondary mathematics education, I am exploring the role of play as both instigator and product of emotions. Play has recognised social, creative, cognitive and especially emotional benefits for young children. However, as students mature, do they still respond to play? Teaching mathematics in secondary school is not normally associated with play, but as illustrated below, can appear in many forms. I will argue that, in the hands of a skilled practitioner, playfulness can benefit teacher, students, and their mathematics learning. This paper explores the unique nature of play in everyday classrooms using a sample of observations and interviews with experienced UK teachers. I conclude that play appears in many subtle forms, playing various roles in a mathematics classroom.

\section{DEFINING PLAY}

"The opposite of play... [ ] ... is not a present reality or work, it is vacillation, or worse, it is depression." (Sutton-Smith 2001)

It is hard to imagine life without some degree of play. Play for me is associated with humour, with laughter and with positive social relationships. Humans are designed to be playful and engagement in play may enrich and engender happiness. In this paper, I explore the role that play takes in learning mathematics. Bibby (2011) claims there is a lack of effective use of play in secondary, so I will assess whether this lack is the case within a sample of UK mathematics classrooms. I will review what we mean by the activity of play in learning, exemplify different dimensions of play as informed by teachers and I will discuss some implications of the disposition of teacher playfulness within a secondary mathematics context.

Definitions and usage for the term play range from 'engaging in activity for enjoyment and recreation rather than a serious or practical purpose', to 'amusing oneself by engaging in imaginative pretence', or 'engaging in an activity without proper seriousness or understanding'. Playing can be participating in a sporting match. Alternatively, one can play a piece or card in a game with rules. One can be in a play, play along in a storyline, play a role, or play someone for a fool. We play instruments or a song, whilst an angler plays a fish. However, play is mostly associated with children learning to be adults as well as with relaxation or merrymaking. Play may be deemed frivolous, not serious or even real, as in 'I was only playing'.

Yet it seems that humans need play. From a list of 24 psychological needs (Murray, 1938), play is located among affection needs. Play is defined as distinct from the other

2015. In C. Andrà \& D. Brunetto (Eds.). Proceedings of the $21^{\text {st }}$ International Conference on Mathematical Views, pp. XXX-YYY. Milan, Italy: Poliprint. 
affective needs of affiliation, nurturance, rejection or succorance, as 'having fun with others'. Thus locating play as a social as well as an individual need. In a seminal text on play, 'Homo Ludens', [Man the player] Huizinga (1949) defines play as,

"a free activity standing quite consciously outside 'ordinary' life as being 'not serious' but at the same time absorbing the player intensely and utterly. It is an activity connected with no material interest, and no profit can be gained by it. It proceeds within its own proper boundaries of time and space according to fixed rules and in an orderly manner. It promotes the formation of social groupings that tend to surround themselves with secrecy and to stress the difference from the common world by disguise or other means." (p.13)

I seek to defining play in context through seeking some essential characteristics to look for, to determine whether an episode in a mathematics classroom really is play. These will frame discussion of episodes selected from classroom observations. Firstly, that the teacher chooses to and directs the play. The focus of my wider research centres on teachers, and this has guided episode selection. Secondly, means or activity is valued more than outcome, so process orientated despite a teacher seeking positive outcomes. Thirdly, that structure and rules emanate from the mind of the teacher as the instigator. Fourthly, there needs to be some imaginative remove from real or serious life, and finally, play needs an alert and active frame of mind (Reifel, 1999) considered here as playfulness. In this paper, I am not considering the whole lesson, which in itself may be viewed as a kind of play; rather the focus is on short episodes from within a lesson.

Distancing play from real life in an educationally purposed context may be problematic. This position also neglects the emphasis within mathematics education on problem solving, and real life examples. Radford (1998) draws on a Vygotskian view of play; that activity in play is neither independent of context nor independent of particular motives. Radford suggests that both motives underpinning the actions in play and plots come from cultural reality, so any dialogue and actions displayed in play will be coherent with an individual's version of cultural reality. This coherence implies, in terms of mathematics teaching, that we can still define activity that has a motive of mathematical learning as play, as this is the contextual reality for a teacher.

\section{THE MULTIPLE ROLES AND VALUE OF PLAY}

Play can support the learning of mathematics through playing by oneself, socially or mathematically. Storytelling of the form 'Once upon a time...' is a domain of childhood, yet playing through storytelling for adults is still a pleasant experience, albeit in forms such as fantasy games, novels and films. Internal monologues and connections formed by engaging in fantasy play are supportive of creative thinking and innovation. Predicting the future, as in imaginative play, is a useful skill that is essential for mathematical problem solving. Play is preparation, by acting, imitating or practicing for perfection. Brown (2008) suggests humans are designed to play because it is advantageous for adaptability. Further, there is a strong association between play and creativity in brain processes. For example, rats lose strategies and risk-taking if 
prevented from engaging in play (Diamond et al., 1964). We know play for young children supports brain development, making connections, brain crafting, firing up and generating passion and drive (Brown \& Vaughan, 2009). Play can also be therapy (in the Freudian sense), which allows re-ordering of people, events and circumstances into patterns, a very mathematically relevant skill. Play in a form appealing to an adult leads to arousal or stimulus seeking and avoids boredom (Mandler, 1984).

Children also learn limits of social interaction through play. Even if play is not just preparation for adulthood, this role is still a dimension of play, one pertinent to adolescents. Engaging in play supports the formation of rituals (rules of ball play) and establishment of norms (rules of the game) (Vygotsky, 1978). Only the form of acceptable play as students mature alters, in line with cultural and social norms. For example, work is deemed a serious business. Play as a social endeavour benefits the balancing of emotions. For example, play can take a role in reduction of conflict, or in encouraging positive emotions in others. In any context, people must adapt and behave in accordance with conscious, shared mental conceptions of what is appropriate, and play can support this aligning. People that play together (such as sports teams or groups with a common purpose) ideally build trust, trust that comes from play signals which may be vocal, facial body or gestural. Play has a communicative role, reducing barriers to communication and reducing personal distance. Belonging and building emotional bonds are one of the main roles of playing together for all ages (Reifel, 1999).

Unsurprisingly, there is far more research about mathematical play in relation to young children rather than teenagers, drawing on a long tradition of play based learning in the UK. Perry and Dockett (2007) write of play specifically in relation to mathematics in early childhood. They suggest that many early mathematical understandings that create meaning will have been formed through play. They emphasise the role that play has in creating a situation supportive of innovation, risk taking and problem solving. Relocating activity in play rather than in 'real life' is useful when learning mathematics. The separation from reality that play allows means that a safe place is created where risks can be taken, supporting a reduction of potential shame or embarrassment, similarly for developing curiosity and for exploration into uncertainties. Such a fictional mode of thinking, and keeping that mode distinct from the literal, is innate to the human mind (Abraham \& Yves von Cramon, 2009).

Play is complementary to learning mathematics in early learning contexts as play has an integrative role within learning, through consolidation and making connections across experiences, or forming new representations. But mathematics and play seem to disconnect as students pass into adolescence. Perry and Dockett (2007) remind us that the role of the teacher is pivotal in making play connections and I would suggest remains pivotal in secondary mathematics. If we want students to enjoy and play whilst learning mathematics, then there needs to be a supportive environment, space and time for encouragement of play. We will see in what follows if the teachers studied for this 
research provide such an environment. However, a contradiction exists in that at the same time as we know play benefits learning, it is possible to teach mathematics without socially experienced or observable play.

\section{HOW DO TEACHERS PLAY IN THEIR LESSONS, AND HOW DO THEY SPEAK OF PLAY?}

I have collected data from interviewing and observing eight experienced UK secondary mathematics teachers. This data includes a post-observation discussion using video recall, discussion centred on episodes selected on the basis of expression of positive emotions by the teacher. Episodes of play are frequent in just a few selected minutes of observation. The examples below illustrate play as it appeared within selected episodes that exhibit the five play characteristics of director, process, choice, remove and frame of mind. The range of examples illustrate imaginary play including nursery behaviours, storytelling, banter, sharing of humour, teasing, puzzles as play, physical play as in modelling, discovery play and in general playfulness in tone, voice and manner. After presenting the examples, I will explore how these forms act to benefit learning in mathematics.

In a lesson about the nth term for sequences (generating $4 \mathrm{n}-2$ from terms), one teacher, Adam, enticed his students into imaginary play. The students enjoy becoming a flock of sheep with a shepherd, "You've got to imagine Mark's got like a funny hat thing, and you're the sheep" [Pointing to class who begin bleating]. A scenario is used to reinforce the concept of $\mathrm{n}$ as natural numbers within sequences. An associative physical form of play emerges as the student positioned as 'shepherd' stands to count his 'sheep'. In the same episode, Adam uses repetition of the phonic form of $\mathrm{n}$, used in early years, to further emphasise the point, "nuh...nuh...nuh...we use nuh. En [n] for number." Further, he encourages the student use of a nursery rhyme ("12345 once I caught a fish alive"). These students are 14 to 15 years old, not primary school children, yet they willingly engage in play, and as one tells the teacher later, "I 'get' algebra now". The rewarded teacher implied he would count sheep again.

Another teacher, Gus, continually engaged his year 7 students in fast paced banter, playing through apparently irrelevant flights of fancy. The imaginative element illustrated below emerged from a serious mathematical point about communicating mathematically, one which gave time for students to finish the preceding task. A slip of tongue over pronouncing the name David in a responsive quip from one of the students led to an enjoyed extended deviation and storytelling relating both the teacher's short grey hair and imminent retirement to Ginola's famous flowing locks.

Teacher Nice one Jeff. No, seriously, did you know David Ginola used to played football for Arsenal?

ALL [Singing] Arsenal are useless... [Inaudible]...

Teacher $\quad . .$. and when he finished... when he finished his footballing career, he got a model... as a hair model... he used to advertise shampoo [more laughter] 
Jeff

Teacher

Funny. You could do shampoo when you finish your teaching. [The students knew Gus was retiring] You could do that. Yeah, can you imagine this saying...? 'Grecian zero, fo
be grey' [more laughter] [Gus has very short grey hair]

As the laughter ended, the whole class spontaneously re-engaged in the mathematics. This pattern happened often in the observed lesson; periods of concentration interspersed with banter, anecdotes and lots of playful laughter. In post observation discussion Gus explains his view of this patterning. He believes that students who enjoy themselves will learn more, reducing anxiety about mathematics.

Edward's form of playing illustrates sharing of humour as selected as humorous by the teacher. He plays a video of a polar bear catching a seal as part of a lesson introducing proportion through animal hunting data. Afterwards he commented;

"It is one of my favourite clips, and I've played that... this is the second time that I've used it, without fail, every class has laughed at the bit where the polar bear pops up its head behind the seal."'(Edward)

Adam in a different lesson is playing a spontaneous humorous con on his students, telling the class that he will ask the exam board if their chosen names for common sequences can be added to the curriculum. This complex example of playing has mathematical purpose and gives the students ownership of the mathematical terminology. It also shows the teacher imagining future pleasure from extending the joke.

"I thought... if they can actually kind of come up with the sequence themselves, rather than me telling them, 'these are square numbers and these are triangle numbers,' then they'll get a bit more ownership of it and remember it more." He adds "So I'll tell them, I've got them tomorrow, I'll tell them 'I've been in touch with the exam board and they've said they'll take that, your definition"' [Laughs]. (Adam)

In the data there are more traditional examples of play, defined as common strategies for teaching that may use games, such as engaging in puzzles. For example, Debbie uses a jigsaw type of puzzle, a Tarsia, as a means of engaging her students in mathematics through problem solving. Debbie comments on playing with her hands as a means of explaining a written problem,

"So I was trying to explain that when it [Aeroplane] hits the ground...[]... it's fallen from the sky, it's got to 180 metres when it has hit the ground, but it has gone down a further 45 , how far has it gone down?...[]... So I was trying to do it with hands, so they sort of got the... that's the sky, that's the ground, it's fallen into the sea further, so... I think she did then go on to answer the question correctly, and she could explain to me why, which was good." (Debbie) She tells of playfulness from an early age, "I can remember when I was very small registering my teddy bears, having them all lined up and taking a register." I observed 
Debbie using her whole body whilst teaching and effectively using mannerisms, noises and gestures usually associated with teaching younger children. For example, at one point, her students join in singing the theme to Balamory, a nursery TV programme.

In interview, Carol talks of play and mathematics in relation to her own mathematical learning. For example, as a child, she entered a magic square competition. This play, in the form of puzzle solving, was encouraged, "He [Dad] recognised that I had an interest, and he sort of perhaps pushed that and promoted that a little bit." Her classroom is bright, with lots of student display work, a teacher form of play, usually more associated with primary and not often high profile in secondary mathematics classrooms. Carol chose for observation an experiential learning lesson, where students played with coins and dice to discover relative frequency.

In summary, as well as play as described above, there are examples of physical body play, playfulness from the teacher, as when Debbie moves her arms to model an aeroplane flight path, or Adam's student sheep. 'The sheep' example also illustrates how imaginative pretend play can appear in a mathematics lesson. Gus, a keen football fan, telling of David Ginola's hair, also takes students on a flight of fantasy. A teacher sharing amusing videos shares pleasure in a playful way, as does choosing exploratory play to teach. There is also a place for neoteny, such as when Adam repetitively says 'nuh' for explaining $\mathrm{n}$ in sequences, uses nursery counting songs, or when Debbie and her class sing a children's TV theme song. These examples illustrate a wide range of play in everyday mathematics classrooms in just a few short episodes. Next I will discuss these episodes in relation to the five characteristics of play, before discussing the implications in terms of deviation from the rules, and any emotional benefits.

\section{THE FIVE CHARACTERISTICS OF PLAY}

The five play characteristics, director, process, choice, remove and frame of mind assume play is about motivation and that play exists on a continuum from pure play to none. The examples selected show the teacher choosing to play and directing the play since this is my specific area of interest. Play as used here is predominantly process rather than product orientated, with examples taken from classroom activity. The students may not be aware of the learning product intended by the teacher. A further defining characteristic in this context is that the structure and rules of play emanate freely from the mind of the teacher. Although the teacher chooses to play, the rules often need to be negotiated, and may, as in the case of Adam, become the norms of the class. In play organised by a teacher, students are not usually able to change rules, which is why Adam's proposed intervention is potentially powerful in terms of ownership of mathematics. Adam, in 'the sheep' story, demonstrates what Vygotsky called 'socio-dramatic play'. This form is among the most complex forms of play, in terms of rules and the playful acting out of roles or scenes. The fundamental rule here is that you must abide by shared understandings of the role that you are playing (Vygotsky, 1978). Examples of imaginative remove from 'real' or 'serious' life appear 
particularly in the observations of Gus or Adam. Play of all sorts has 'time in' (period of fiction) and 'time out' (temporary return to reality), though this distinction is more obvious for some forms of play. Gus has a clear distinction in his teaching between 'time in' and 'time out'. In this case, time out is engaging in mathematics. Yet during 'time in' he does not say, 'I am just playing', since to acknowledge that play is play removes the magic spell. Gus seamlessly switches between 'time in' and 'time out', and at times, the distinction is blurred. The fifth characteristic relates to willingness, that a teacher needs a propensity for play. It seems that in all these examples, enjoyment of play forms when participants have an alert and active frame of mind. Therefore, an engaging pace is important for effective play in a mathematics classroom. This dimension is apparent in the selected episodes, as is a disposition to engage in play on the part of the teacher.

\section{IMPLICATIONS}

Perry and Dockett (2007), although chiefly discussing primary mathematical play, consider the ideal relationship between teacher and students that is play supportive. They suggest that students should not be unguided, as an active teacher role can deepen the sophistication of play. They suggest a teacher of mathematics should be a provocateur, who challenges, generates situations through questions, or surprises for example. Yet modelling playfulness in conjunction with learning mathematics only works if the teacher is so disposed. I would suggest that deviation is associated with play. A teacher can decide to deviate from norms of their classroom, to be creative, accept the associated risk and vulnerability and use deviative forms of play as a teaching strategy. Goffman (1997) suggests that there may be less potential for conflict between teacher and students where some expected roles have been abandoned. In this case, and others, teachers have more impact as not all teachers are playful. On an individual level, play draws and fascinates the player precisely because it is structured by rules that the player herself or himself has invented or accepted.

Whilst collecting the data, I recorded the teacher's galvanic skin response (GSR) using a sensor, with an interest in experienced internal emotions whilst teaching. The sample is small, and the inconclusive results require further investigation, but there were some dips in the associated graphs (reduced stress or excitement) associated with episodes of intense laughter for Adam and Gus. Engaging in play might even be calming for a teacher as Gus suggests in interview. "...there are bits which are stressful, but when the class and I are working together well, then it's great. We've got to do... all we do is just work together and it's relaxing." There seems to be a link between positive emotions and reduction in stress, but because play is not a response to external demands or immediate strong biological needs, the person at play is relatively free from the strong drives and emotions experienced as pressure or stress. Yet there is a contradiction. If play relaxes, managing play in classroom context requires teacher intensity and energy. The pace during episodes is generally faster, more dynamic, and 
this may add to a need for intense management. The teacher also has to manage behaviour carefully whilst engaging in extended scenarios, especially as play may appear as an abandonment of expected rules. It is easy to see how the students might lose the mathematical purpose whilst experiencing 'time in'.

Mandler's (1984) suggestions for the purposes of emotions may correlate to some of the purposes of play. If so, then play, as for emotions, can help to deal with mismatches between actual and intended actions and to address discrepancies or uncertainties as well as having an adaptive role. Emotions also serve to process first encounters that may be strange or unusual events, these encounters too may be a source of arousal. Therefore, teacher initiated play in a mathematics classroom can act to bring positive emotions to the fore. We know students talk of boredom, but experienced teachers experience boredom too. Play can work against this.

Play, as expressing positive emotions, acts to reduce emotional distances. In any power relationship distances are inevitable, in this case between teacher as authority and student as child. Play, used appropriately, may act to break down such barriers and play a balancing role for both students and teachers. If we consider the teacher as a mediator between mathematics and students, then play may act to facilitate this role, especially for experienced teachers. So far, I have portrayed play as positive. However, not all the observed teachers engaged in identifiable forms of play. For example, Helen used a game to teach, but this was not considered play, by myself or Helen, as the primary purpose was to support exam success. This raises two questions: what might act to prevent play in the forms described above? And, given barriers and risks to play, why do some teachers still engage in play?

\section{SECONDARY MATHEMATICS LESSONS WITH NO OBSERVABLE PLAY}

Not all the teachers observed and interviewed spoke about or used play. There seem to be limitations in the forms of play observed, or at least differences in teacher views of play. A more traditional view might be to see play simply as games or as a teaching tool. For example, Helen, a strategic outcome orientated teacher, separates play and learning. Playing games and activities (she says) can be allowed only after exams because they are high risk in terms of paying attention to exam success, even to the point of time wasting.

“...we are coming up towards a test,...you kind of want to make every second really focussed and really count, and really relevant and really going to help them with that test rather than perhaps being a bit more exploratory and a bit more outside the curriculum, outside the box." (Helen)

This may be a common position even when speaking to others of the rhetorically acceptable advancement of play within mathematics teaching, a discrepancy because they do not really believe in the value of play. One reason for not engaging in play is that it can be chaotic (Perry \& Dockett, 2007) and hence entail risk. Further, playfulness takes intensity and effort to sustain. So there has to be an effective reward 
for engagement in play, especially social play in a work heavy context such as teaching.

As discussed above, play is dependent on willingness to potentially 'look silly', as well as on what is important to a person, one's own values in relation to the teaching of mathematics. Engaging in play involves revealing self, so there is a degree of vulnerability involved in playing in the context of a mathematics classroom. You are also risking damaging your relationship with a group of students if you 'pitch' it wrong. Teachers also risk criticism of neoteny, as European culture is one where childishness is often a criticism. Yet Brown (2008) suggests that humans are adaptable because they are among the most neotenous species on Earth. There are also potential cultural or social barriers to play. For example, that play is a waste of time, or associated with guilt for not 'working', or a common view that play is only a rehearsal for adulthood and has no place as one gets older and dignity prevails.

\section{BENEFITS FOR TEACHERS WHO ENGAGE IN PLAY}

Yet if engaging in play works as for some teachers, the rewards are significant. Play can balance and enhance relationships through shared satisfaction and enjoyment. Adam or Gus especially use play, where play serves to break and divide a lesson and keep the attention of students. They seek novelty, and have found an effective unique teaching style, one that generates and supports positive learning.

One reason for engaging in play might be that when routine sets in, a self-aware teacher is likely to seek novelty and deviation, different ways of playing to entertain both themselves and students. It may also be the case that prior experiences have shown them that it is an effective strategy for them. Play experienced as leading to pleasure will trigger seeking of similar emotions and hence becomes an enticement to engage in more similarly rewarding activities. Therefore playful teachers are willing to risk (risk is part of play too), but that they have found that they can use play to model connective learning of mathematics through playfulness and humour. Therefore, they expect enjoyment. The expression of positive emotions evoked by an expectation of enjoyment is likely to make the risk successful, as the students see this modelling and expectation, and respond positively.

\section{CONCLUSIONS AND IMPLICATIONS}

The evidence points towards play being good for adolescents, mentally and physically, and, as I have argued, mathematically. Although I am converted to the value of play, a question remains as to whether the effective use of playing by teachers in secondary mathematics is a disposition, or whether it can be learnt. I would suggest that balancing play with managing classroom conduct is an art rather than a skill. The implications from the discussion above suggest play requires willingness, but also confidence, self-discipline and energy. A teacher needs to be willing to use their "divinely 
superfluous neurons" (Brown \& Vaughan, 2009). Certainly play is not passive. What may be of importance is the modelling activity implied by engaging in play, as for effective teaching of mathematics

Playfulness models a valuable form of engagement in mathematics, one supportive of experiment and creativity that is means rather than outcome focussed. It is also a form of teaching that generates positive emotions, but also positive emotions promote playfulness. If harnessed appropriately to the teaching and learning of mathematics then we have a very powerful tool to add to the teacher's repertoire, one which retains teacher interest, sustains student engagement and is socially supportive. So yes, there a place for serious frivolity in the secondary mathematics classroom.

\section{References}

Abraham, A., \& Yves von Cramon, D. (2009). Reality = Relevance? Insights from Spontaneous Modulations of the Brain's Default Network when Telling Apart Reality from Fiction. PLoS ONE, 4(3).

Bibby, T. J. (2011). Education - An 'impossible profession'? London: Routledge.

Brown, S. L., \& Vaughan, C. C. (2009). Play: how it shapes the brain, opens the imagination, and invigorates the soul. New York: Avery.

Brown, T. (2008). Lacan, subjectivity and the task of mathematics education research. Educational Studies in Mathematics, 68(3), 227-245.

Diamond, M. C., Krech, D., \& Rosenzweig, M. R. (1964). The effects of an Enriched Environment on the Rat Cerebral Cortex. J. Comp. Neurol, 123, 111-119.

Goffman, E. (1997). The Goffman reader. Malden, Mass.; Oxford: Blackwell.

Huizinga, J. (1949). Homo ludens: a study of the play-element in our culture. London, Routledge \& Kegan Paul.

Mandler, G. (1984). Mind and body: psychology of emotion and stress, New York, Norton.

Murray, H. A. (1938). Explorations in personality: a clinical and experimental study of fifty men of college age. New York: Oxford University Press.

Perry, B., \& Dockett, S. (2007). Play and mathematics. Association of Australian mathematics teachers. www.aamt.edu.au/content/download/7299/94431/file/play.pdf [Accessed 01/09/2015]

Radford, L. (1998). On culture and mind: A Post-Vygotskian semiotic perspective with an example from Greek Mathematical thought. Paper presented at the 23rd Annual Meeting of the Semiotic Society of America, Victoria College, University of Toronto.

Sutton-Smith, B. (2001). Reframing the Variability of Players and Play. In S. Reifel (Ed.), Theory in Context and Out. Play and culture studies (Vol. 3). Westport, CT, USA: Greenwood Publishing Group.

Vygotsky, L. S. (1978). The Role of Play in Development. In V. J.-S. M. Cole, S. Scribner, \& E.Souberman (Ed.), Mind in Society: The Development of Higher Psychological Processes (pp. 92-104). (Reprinted from: 1933), Cambridge, MA: Harvard University Press. 